\title{
RURAL-URBAN MIGRATION AND CONCENTRATED EMPLOYMENT PROGRAMS: A COMMENTARY
}

\author{
Hugh W. Knox \\ University of North Carolina (Chapel Hill)
}

The most critical observation I can make with regard to these two papers is that neither of them demonstrates how their main content relates to their conclusions. It is not clear enough how the analysis and empirical findings in each paper imply the policy conclusions which the authors suggest. There exists a question as to what the value-added dimensions of the papers are with regard to their conclusions. Phrased another way, was it really necessary to conduct the research contained in these papers in order to generate the policy conclusions?

In the paper by Floyd and Robertson, the authors establish that people a re willing to commute up to one hundres miles, although most people in their study commute less than fifty miles. This is a reasonable but not startling conclusion. But to go from this finding to a policy recommendation of subsidizing rural commutation as a cure for "current inner-city urban problems" requires the acceptance of many intervening as sumptions which I am not willing to make.

My fundamental disagreement relates to the implied causal chain between migration and urban ills. Firstly, if past migration really was the major cause of the urban crisis, which I doubt, then it would seem that Floyd and Robertson might speculate on how many people of what race, age, and education would be likely to remain in rural areas given a subsidized commutation policy. Secondly, if we are seriously interested in alleviating the urbancrisis through a transportation policy, why not subsidize urbantransportation systems? What is so special about rural workers that they should receive a subsidy over and above whatever subsidy is implicit in the Interstate Highway System? Floyd and Robertson do not address these issues, but they are crucial links between their research findings and their policy conclusions.

Another issue which could use more discussion is the nature of the subsidy called for by Floyd and Robertson. The comment that "these subsidies would not have to be of a permanent nature" seems tenuous to me. What is so rare as a revoked subsidy? Another problem is that the evidence used to demonstrate that relocation is very costly is not germane. The projects cited were for unemployed and underemployed labor whereas the data which the authors use relates to relatively high wage and high skill industry.

My last comment on this paper is a suggestion that Floyd and Robertson pursue the notion that their subsidy be based on state priorities rather than federal. If it is true that someareas of the country wish to remain relatively dispersed, it would seem more equitable for those same areas to generate the subsidies to maintain dispersion of economic and residential patterns. Let these regions have the benefits of dispersion and let these regions pay the opportunity costs of maintaining such patterns. It is not clear from this paper why the Federal govenment should provide the subsidies.

Turning to the Revzan paper, I liked the use of transitional probabilities to link segments of the training process, but there is some question in my mind regarding the number of times a person went through one link. The program description indicates that individual trainees could repeat any training level but it is not clear from the paper how this affected the transitional probabilities and these probabilities are an essential part of the program 
evaluation.

Another methodological question relates to whose perspective is important in evaluating the success of the program. It may be that the unskilled are more riskaverse than those evaluating the program. If this is true then the use of average income change to measure benefits could overstate the benefits of the program. The people who will be affected by the benefits of the programs will not see these benefits as being so attractive as the people administrating the program.

With regard to the results of the econometric analysis, I was not so convinced as the author that the results were of analytic significance. The only variable which was consistent throughout the equations was the level of entering income. The inclusion of other variables increased the proportion of explained bariation, but the coefficients of these variables were not significant. Consequently, it is uncertain whether or not the equations actually explain the underlying structure. Policy based upon these results may not be successful.

Revzan establishes that those sectors of the program which were successful in benefit-cost terms related to basic education and basic vocational training. The other sectors, such as on-the-job-training, were not as successful. This being the case, I would expect the policy conclusions to reflect this, that is, reallocate resources to successful programs and de-emphasize the other sectors. However, the conclusions relate more to the need for better accounting devices which would provide more and better data. It may be necessary to treat these results as first approximations and to call for further research, but I would like some assurance that further research would have more direct relevance for policy.

In conclusion, both of these papers have contributed some information to the problems at hand, but the level of that information, given the complexities of the problems, does not allow the kinds of conclusions which both papers reach. I hope that the authors will pursue some of the other dimensions of these problems which I have noted. 